\title{
Implementación y evaluación de dos métodos de conservación y generación de la base de datos del banco de cepas y genes del Instituto de Biotecnología de la Universidad Nacional de Colombia (IBUN)
}

\author{
Sandra Liliana Parra Huertas ${ }^{1 *}$, Maria Marcela Pérez Casas ${ }^{1}$, Mauricio Bernal Morales ${ }^{2}$, \\ Zulma Suárez Moreno², Dolly Montoya Castaño². \\ Universidad Colegio Mayor de Cundinamarca', Instituto de Biotecnología de la Universidad Nacional², Bogotá, Colombia. \\ Correspondencia: sandraparra6@hotmail.com, marceperez84@yahoo.com
}

Recibido : 09-05-2006 /Aceptado : 02-06-2006

\begin{abstract}
Resumen
76 cepas de las familias Enterobacteriaceae y Pseudomonadaceae fueron conservadas por el método semistock en papel filtro y 68 de las mismas por el método stock de criopreservación, en el banco de cepas y genes del Instituto de Biotecnología de la Universidad Nacional de Colombia (IBUN). La eficacia de los métodos de preservación se realizó mediante la evaluación de la viabilidad a las 24 horas de conservación y fue calculado el porcentaje de recuperación. En conclusión, la preservación en papel filtro y criopreservación son adecuados métodos semistock y stock, respectivamente; ya que el 73.7\% de los microorganismos de la familia Enterobacteriaceae y el $82.3 \%$ de los microorganismos de la familia Pseudomonadaceae, presentaron un porcentaje de recuperación mayor al 50\%. Por otra parte, se implementó una base de datos elaborada en el software Access ${ }^{\circledR}$, la cual se implemento con éxito en el IBUN y en la página Web de la Universidad Nacional de Colombia en la dirección electrónica www.ibun.unal.edu.co/instituto/cepario, que esta disponible al público en general.
\end{abstract}

Palabras claves: criopreservación, viabilidad, cultivo semistock, cultivo stock, base de datos.

\begin{abstract}
76 strains of the family Enterobacteriaceae and Pseudomonadaceae were conserved by filter paper semistock method and 68 strains by Cryopreservation stock method in the bank of strains and genes of Biotechnology Institute of the Universidad Nacional de Colombia (IBUN). The effectiveness of methods was tested for the viability at 24 hours after preservation and was calculated the recovery percentage. Thus in conclusion, the preservation in paper filter and cryopreservation are suitable semistock and Stock methods, respectively; because 73.7\% of family Enterobacteriaceae microorganisms and 82.3\% of family Pseudomonadaceae microorganisms, presented a high recovery percentage greater $50 \%$. In addition, was implemented a strain bank data base made in software Access ${ }^{\circledR}$, in Biotechnology Institute and Universidad Nacional de Colombia Web page www.ibun.unal.edu.co/instituto/cepario. It is available for general public.
\end{abstract}

Key words: cryopreservation, viability, semistock culture, stock culture, database 


\section{Introducción}

A lo largo del siglo XX la tradición institucional de la investigación microbiológica en Colombia ha estado centrada en brindar soluciones a problemas en los campos de la salud y la agricultura, dejando un invaluable legado y un conjunto de colecciones de microorganismos que constituyen la base de futuras investigaciones. Entre las más importantes se encuentra el banco de cepas y genes del Instituto de Biotecnología de la Universidad Nacional de Colombia.

Es importante entender que para el mantenimiento de un banco como este, los cultivos deben permanecer puros y homogéneos bajo condiciones que aseguren la estabilidad microscópica, macroscópica, bioquímica, fisiológica y genética. Hay gran número de métodos descritos para la preservación microbiana. Los criterios a ser considerados para la selección del método son la viabilidad, pureza, costos del proceso, cantidad de cultivo (para la producción de microorganismos) y frecuencia de uso (1). Por seguridad, y para reducir la perdida de microorganismos, cada cepa se debe mantener en dos métodos de conservación diferentes, uno stock, y otro semistock. Dentro de los métodos que dan una preservación estable, están la criopreservación y la preservación en papel filtro. El propósito del presente estudio es implementar y evaluar dos métodos de conservación y generar la base de datos del banco de cepas y genes del IBUN.

Para dar respuesta al objetivo propuesto, el proyecto se dividió en seis etapas: en la primera etapa se efectuó una identificación de los microorganismos del cepario, en la segunda se realizó la recuperación de los mismos y en la tercera se determinó los microorganismos a conservar. Posteriormente, en la cuarta etapa se efectuó la conservación de los microorganismos, en la quinta se evaluó la eficacia de cada método y en la última etapa se documentaron los protocolos y se generó la base de datos, con la información recopilada durante las etapas anteriores.

Los resultados logrados fueron la conservación adecuada de los microorganismos de la familia
Enterobacteriaceae y Pseudomonadaceae recuperados, manteniéndose las propiedades de viabilidad, homogeneidad y valor de la propiedad.

Se actualizaron los protocolos de recuperación, viabilidad y conservación; además se generó una base de datos en el software Access ${ }^{\circledR}$, que se implementó en la página Web del Instituto de Biotecnología de la Universidad Nacional, para que pueda ser consultada por el público en general.

\section{Materiales y métodos}

1. Microorganismos: las cepas microbianas fueron recuperadas del banco de cepas y genes del IBUN, conservadas por el método de criopreservación a $-70^{\circ} \mathrm{C}$, y a $4^{\circ} \mathrm{C}$ en condiciones de liofilización y papel filtro.

\section{Primera etapa: Identificación de los} microorganismos. En esta primera etapa se efectuó una identificación de los microorganismos del banco, los cuales fueron estratificados según el método y la temperatura de conservación. Debido a la gran cantidad de cepas de Escherichia coli, este género se separó de la familia Enterobacteriaceae para facilitar el análisis de los resultados.

\section{Segunda etapa: Recuperación de los} microorganismos. Se realizó una recuperación de los microorganismos, teniendo en cuenta el esquema propuesto por Espitia (2) y Díaz (3). Para la recuperación de los microorganismos conservados a $4^{\circ} \mathrm{C}$, los viales fueron rehidratados con $1.5 \mathrm{ml}$ de caldo BHI (Brain Heat Infusión Oxoid Ò) asépticamente durante treinta minutos, posteriormente se dispensaron $0.5 \mathrm{ml}$ de la suspensión en $5 \mathrm{ml}$ de caldo BHI y se incubaron a $37^{\circ} \mathrm{C}$ por $24 \mathrm{~h}$. En el caso de las cepas conservadas a $-70^{\circ} \mathrm{C}$, los viales fueron descongelados lentamente y mantenidos en baño de hielo, para

www.unicolmayor.edu.co 
tomar $0.1 \mathrm{ml}$ del cultivo e inocularlo en $5 \mathrm{ml}$ de Caldo $\mathrm{BHI}$, que luego fue incubado a $37^{\circ} \mathrm{C}$ por $24 \mathrm{~h}$.

Con el fin de observar las características macro y microscópicas, los cultivos fueron sembrados en Agar BHI, e incubados a $37^{\circ} \mathrm{C}$ por $24 \mathrm{~h}$. Para descartar posibles contaminaciones se realizaron repiques sucesivos de la colonia característica. Al cultivo puro se le realizó para la caracterización morfológica y bioquímica, coloración de Gram, pruebas bioquímicas y siembra en Agar Mac Conkey (MERCK $\left.{ }^{\circledR}\right)$ en el caso de las enterobacterias; y en agar Cetrimide (Pseudomonas Cetrimide Agar USP, OXOID ${ }^{\circledR}$ ), en el caso de Pseudomonas. Finalmente, se realizaron repiques del cultivo puro en Agar LB (Lurian Bertain: triptona $10 \mathrm{~g} / 1$, extracto de levadura $5 \mathrm{~g} / 1, \mathrm{NaCl} 10 \mathrm{~g} / 1$ ), para su posterior conservación.

\section{Tercera etapa: Determinación de los} microorganismos a conservar. Luego de aislados los microorganismos, ques se encontraban a $4^{\circ} \mathrm{C}$ y a $70 \mathrm{oC}$, se determinó la cantidad de microorganismos a conservar. Enseguida se clasificaron las cepas según los métodos de conservación más adecuados y se estableció la conservación por el método Stock de Criopreservación a $-70^{\circ} \mathrm{C}$ y por el método Semistock en papel filtro.

\section{Cuarta etapa: Conservación de los} microorganismos. La conservación por el método Semistock en papel filtro se realizó basada en el protocolo propuesto por Kirsop (4). Este método mantiene la viabilidad de los microorganismos trabajados (Enterobacterias y Pseudomonas) en un intervalo de 4 años, es fácil de realizar y económico, a diferencia de la desecación en disco de gelatina que también se ensayó y resultó ser más dispendiosa y costosa. Para ello se tomaron 4 viales de $2 \mathrm{ml}$ por cada cepa a conservar que corresponden a la viabilidad de 24 horas, 2 meses, 6 meses y un año; y se adicionaron a cada uno 15 discos de papel filtro Whatman $\mathrm{N}^{\circ} 4$ de 5 $\mathrm{mm}$, los cuales se esterilizaron a $121^{\circ} \mathrm{C}$ por $15 \mathrm{minu}$ - tos. Se realizó un cultivo en caldo BHI incubado a $37^{\circ} \mathrm{C}$ en agitación a $200 \mathrm{rpm}$ y con una densidad óptica de 0.4-0.5 leído en un espectrofotómetro (Spectronic 2000) a 600nm. Se tomaron $0.1 \mathrm{ml}$ de cada uno de los cultivos y se agregaron a los viales previamente preparados realizando una buena homogenización y se almacenaron a $4^{\circ} \mathrm{C}$.

La criopreservación a $-70^{\circ} \mathrm{C}$ se seleccionó como método stock, debido a que a diferencia de la liofilización, este es un proceso rápido, con baja contaminación, poco laborioso, económico y mantiene las propiedades genéticas de los microorganismos que contienen plásmidos. El proceso se realizó según lo propuesto por Frank P (6). Se prepararon cinco viales por cada cepa que corresponden a la viabilidad de 24 horas, 6 meses, 1 año, 2 años y 5 años, en los cuales se dispensó $0.8 \mathrm{ml}$ de medio de preservación recomendado por MacFaddin (7) y Gherna (8) (Caldo Tripticasa de Soya $3 \mathrm{~g}$, Glucosa $0.5 \mathrm{~g}$, Leche descremada en polvo 2g, Agente crioprotector (Glicerol $10 \mathrm{ml}$ ), Agua destilada $990 \mathrm{ml}$; esterilizado a 10 libras de presión por $10 \mathrm{~min}$ ); con modificación en el agente crioprotector para E.coli, usando Dimetilsulfoxido (DMSO) según lo recomendado por Sharp (9). Posteriormente de cada una de las cepas se realizó un cultivo en caldo $\mathrm{BHI}$ incubado a $37^{\circ} \mathrm{C}$ con agitación de $200 \mathrm{rpm}$, hasta alcanzar una densidad óptica de 0.8 a $600 \mathrm{~nm}$, leído en un espectrofotómetro (Spectronic 200); de este cultivo se tomaron $0.8 \mathrm{ml}$ que fueron suspendidos en $0.8 \mathrm{ml}$ del medio de preservación previamente preparado en los viales, realizandose luego una homogenización por vortex durante $10 \mathrm{seg}$. Finalmente, los viales fueron refrigerados a $4^{\circ} \mathrm{C}$ por 15 minutos para un periodo de equilibración e inmediatamente congelados a $-70^{\circ} \mathrm{C}$.

\section{Quinta etapa: Eficacia del método de} conservación. Con el objetivo de evaluar la eficacia del método de conservación se realizó un recuento inicial de cultivo y un recuento a las 24 horas de conservación, con los cuales se calculó el porcentaje 


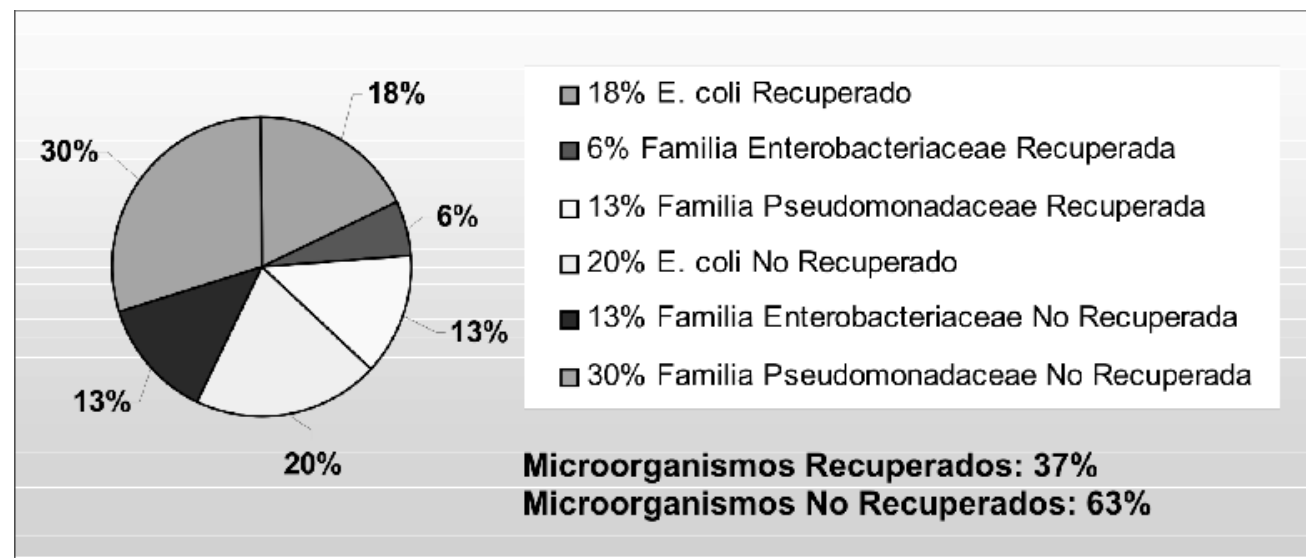

Figura 1. Porcentaje de recuperación y pérdida de los microorganismos que estaban conservados a $4^{\circ} \mathrm{C}$ en papel filtro y liofilización.

Tabla 1. Microorganismos que se encontraban conservados $4^{\circ} \mathrm{C}$ y a $-70^{\circ} \mathrm{C}$.

\begin{tabular}{lccc}
\hline \multicolumn{1}{c}{ Microorganismos } & \multicolumn{2}{c}{ Conservadas a $4^{\circ} \mathrm{C}$} & Conservadas a $-70^{\circ} \mathrm{C}$ \\
& Liofilizadas & Papel Filtro & Criopreservadas \\
\hline Escherichia coli & 29 & 1 & 51 \\
Familia Enterobacteriaceae & 15 & 1 & 10 \\
Familia Pseudomonadaceae & 34 & 0 & 8 \\
\multicolumn{1}{c}{ Total } & 78 & 2 & 69 \\
\hline
\end{tabular}

de recuperación. El número inicial de células se determinó, realizando diluciones desde $10^{-2}$ a $10^{-6}$, para papel filtro, y hasta $10^{7}$, para criopreservación, en agua peptonada (Merck ${ }^{\circledR}$ ); se sembraron $0.1 \mathrm{ml}$ de las ultimas dos diluciones en placas de agar LB, por duplicado, extendiéndolas con un asa de Drigalsky por toda la placa hasta una absorción completa y se incubaron a $37^{\circ} \mathrm{C}$ por $24 \mathrm{~h}$. Se realizó el recuento de las diluciones y multiplicó por el factor de dilución correspondiente para obtener el resultado en UFC $/ \mathrm{ml}$. A las 24 horas de conservación se evaluó el número de células viables para cada una de las cepas tomando para papel filtro dos discos equivalentes a $0.01 \mathrm{ml}$ y suspendiéndolos en $0.99 \mathrm{ml}$ de agua peptonada estéril, realizando diluciones hasta $10^{-6}$. En el caso de los viales conservados en criopreservación, se descongelo lentamente el vial de las 24 horas, tomando $0.01 \mathrm{ml} \mathrm{de}$ éste, realizando diluciones hasta $10^{-7}$ y siguiendo el mismo proceso que para el recuento inicial.

7. Sexta etapa: Documentación de protocolos y diseño e implementación de la base de datos. $\mathrm{A} 1$ mismo tiempo que se recuperaron los microorganismos, se elaboraron los protocolos de recuperación, viabilidad y conservación. La base de datos fue estructurada según lo planteado por Espitia (2) y otras bases de datos consultadas; y elaborada mediante el software Access ( ingresando los resultados generados en los procesos.

\section{Resultados}

\section{Primera etapa: Identificación de los} microorganismos del banco. La identificación de los microorganismos del cepario que se encontraban a $4^{\circ}$ $\mathrm{C}$ y a $-70{ }^{\circ} \mathrm{C}$, se presenta en la Tabla 1 .

\section{Segunda etapa: Recuperación de los} microorganismos.

2.1 Microorganismos conservados a $4^{\circ} \mathrm{C}$. El porcentaje de microorganismos recuperados fue del $37 \%$, de estos corresponden un $18 \%$ a $E$ coli, un $6 \%$ a las otras especies de la familia Enterobacteriaceae y un $13 \%$ a la Pseudomonadaceae; sin embargo, el 63\% de los microorganismos no fue recuperado, correspondiendo un 


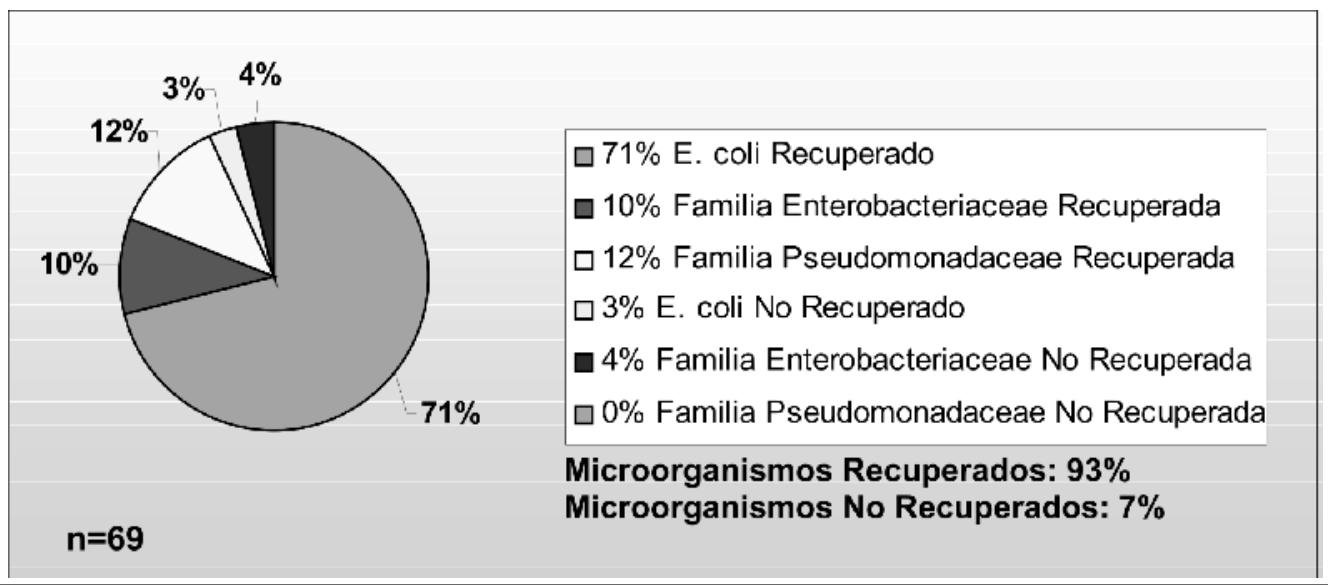

Figura 2. Porcentaje de recuperación y pérdida de los microorganismos que estaban criopreservados a -70ㄷ․

$20 \%$ a $E$ coli, un $13 \%$ a las otras especies de la familia Enterobacteriaceae y un $30 \%$ a la Pseudomonadaceae, Figura 1.

Lo anterior indica que el método de liofilización no asegura un $100 \%$ la recuperación de las cepas por largos períodos de tiempo. Sin embargo, la única cepa de $E$. coli que estaba conservada en papel filtro, logro ser recuperada indicando que este método conserva mejor la viabilidad, aunque por pocos periodos de tiempo.

Se pudo observar además, que cepas de E. coli como HB 101, DH10B, K94 y PKR 2013 fueron las que más se conservaron viables y estables en liofilización. Contrario a lo sucedido con las cepas JN, JPN, CP, NN y SLM, las cuales no se pudieron recuperar de liofilización pero si de criopreservación, indicando que este último es el método de conservación más adecuado para estas cepas. Sin embargo, cabe anotar que en cepas como PRK 2013/98, se pudo recuperar una sola de las dos replicas existentes, lo cual indica que factores diferentes al tipo de cepa afectaron su viabilidad y estabilidad, tales como las condiciones de almacenamiento y de conservación.

También, se observó que Citrobacter freundii, Providencia rettgeri, Pseudomana putida y Pseudomona fluorescens, son microorganismos que no deben conservarse en liofilización, ya que no se pudieron recuperar, contrario a Proteus vulgaris y Morganella morganii que se recuperaron de liofilización y no de criopreservación.
Respecto a la homogeneidad del cultivo, que corresponde a que se trata de un cultivo puro (5), se observó que la contaminación en el método de liofilización se presento en la mayoría de las cepas que se recuperaron, teniendo que realizar repiques sucesivos para su purificación. Aunque se debe tener en cuenta que estos microorganismos se encontraban conservados desde hace aproximadamente 5 años.

\subsection{Microorganismos que se encontraban con-} servados $\boldsymbol{a}-70^{\circ} \mathrm{C}$. La conservación a $-70^{\circ} \mathrm{C}$ es un método otock que mantiene la viabilidad por largos periodos de tiempo en la mayoría de cepas, ya que el porcentaje total de recuperación fue del $93 \%$, correspondiendo el $71 \%$ a E. coli, el $10 \%$ a las otras especies de la Familia Enterobacteriaceae y el 12\% a la Familia Pseudomonadaceae, Figura 2; por lo cual el IBUN lo ha seleccionado como el método ideal para conservar sus microorganismos.

En la criopreservación a $-70^{\circ} \mathrm{C}$ la propiedad de homogeneidad (5), fue adecuada, tanto para E. coli como para Pseudomonas, ya que no presento contaminación, en la mayoría de los cultivos que se recuperaron. Contrario a las Enterobacterias que presentaron una mayor contaminación.

Por otra parte el valor de la propiedad (5) se mantuvo en todas las cepas $\left(4^{\circ} \mathrm{C}\right.$ y $\left.-70^{\circ} \mathrm{C}\right)$ recuperadas, ya que presentaron intactas sus principales propiedades bioquímicas, macro y microscópicas. 
Tabla 2. Cepas a conservar en método stock y semistock.

\begin{tabular}{|lc|}
\hline \multicolumn{1}{|c}{ Microorganismos } & $\begin{array}{c}\text { Cantidad de } \\
\text { Cepas }\end{array}$ \\
\hline Escherichia coli & 54 \\
Otras especies de la Familia & 10 \\
Enterobacteriaceae & 12 \\
Familia Pseudomonadaceae & 76 \\
\hline \multicolumn{1}{c}{ Total } & 76 \\
\hline
\end{tabular}

\section{Tercera Etapa: Determinación de los micro-} organismos a conservar. Se recuperaron en total 54 cepas de E. coli, 10 de otras especies de la Familia Enterobacteriacea Enterobacterias y 12 de la Familia Pseudomonadaceae, Tabla 2.

\section{Cuarta Etapa: Conservación de los} microorganismos.

\subsection{Método semistock de preservación en papel} filtro. El método semistock de preservación en papel filtro fue adecuado para la mayoría de microorganismos conservados, debido a que un $79 \%$ de estos presento porcentajes de recuperación altos, mayores al 50\%; correspondiendo un $53 \%$ a E.coli, un $13 \%$ a la familia Enterobacteriaceae y un $13 \%$ a la familia Pseudomonadaceae. Solo un 21\% del total de microorganismos presentaron un porcentaje de recuperación bajo, menor al 50\%, Figura 3.

Las cepas de E.coli C-600, HB 101 PBR 323 y 327, MX RP4 y KL 16 fueron las que menos resistieron la conservación en papel filtro debido probablemente a sus características genéticas modificadas, como por ejemplo la cepa MX RP 4 que contiene el plásmido RP4 de $54 \mathrm{Kbs}$ o la E. coli KL16 que contiene el bacteriófago KL16 según lo presentado por Silva (10).

Finalmente en todas las cepas conservadas de Enterobacterias y Pseudomonas, se mantuvo las propiedades de homogeneidad y viabilidad.

\section{Quinta Etapa. Método stock de} criopreservación a $-70^{\circ} \mathrm{C}$. La criopreservación a $-70^{\circ} \mathrm{C}$ es un método stock adecuado para la mayoría de microorganismos conservados, pues el $81 \%$ del total de microorganismos presento un porcentaje de recuperación mayor al $50 \%$, correspondiendo un $71 \%$ a E.coli, un $9 \%$ a la familia Enterobacteriaceae y un $1 \%$ a la familia Pseudomonadaceae. Solo un 19\% del total de microorganismos presentaron un porcentaje de recuperación bajo, menor al 50\%, Figura 4 . Sin embargo, de las doce cepas de la Familia Pseudomona-daceae recuperadas, únicamente se conservaron cuatro, debido a que el resto de cepas no logró el crecimiento adecuado

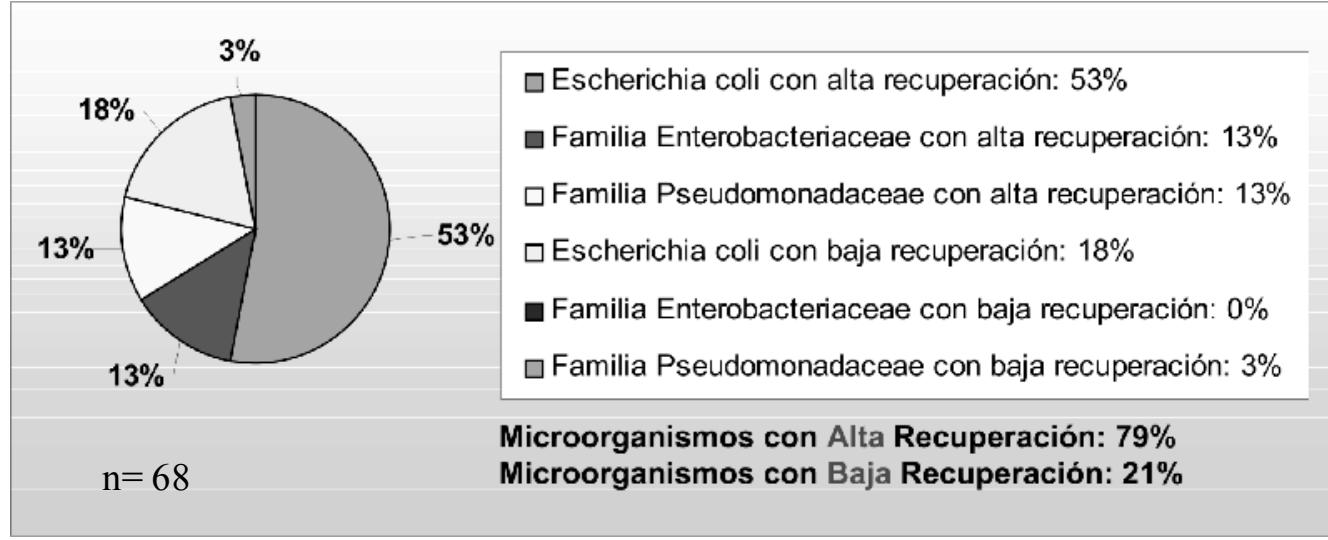

Figura 3. Porcentaje de recuperación a las 24 horas de conservación en papel filtro. 
Tabla 3. Estratificación de las cepas para la comparación de los métodos de conservación evaluados.

\begin{tabular}{cl}
\hline \multicolumn{1}{c}{ Grupo } & \multicolumn{1}{c}{ Especificación } \\
\hline Grupo 1 & $\begin{array}{l}\text { Microorganismos con una Recuperación Alta tanto en Criopreservación } \\
\text { como en Papel filtro. }\end{array}$ \\
Grupo 2 & $\begin{array}{l}\text { Microorganismos con una Recuperación Alta en Criopreservación pero } \\
\text { Baja en Papel filtro }\end{array}$ \\
Grupo 3 & $\begin{array}{l}\text { Microorganismos con una Recuperación Alta en Papel filtro pero Baja en } \\
\text { Criopreservación }\end{array}$ \\
Grupo 4 & $\begin{array}{l}\text { Microorganismos con una Recuperación Baja tanto en Criopreservación } \\
\text { como en Papel filtro }\end{array}$ \\
\hline
\end{tabular}

(densidad óptica de 0.8). De las cuatro cepas conservadas, solo una presento un porcentaje de recuperación alto, mayor al 50\%, lo que indica que aunque se logro el crecimiento adecuado para la criopreservación, este método no es el más eficaz para este tipo de microorganismos.

Además se encontró que en todas las cepas conservadas $\mathrm{a}-70^{\circ} \mathrm{C}$, se preservaron las propiedades de homogeneidad y viabilidad, lo que indica que es un buen método de preservación, pues conservo los cultivos puros y viables.

\section{Comparación de los métodos de conserva-} ción en papel filtro y criopreservación a $-70^{\circ} \mathrm{C}$, en cuanto a porcentaje de recuperación. Para la comparación de los métodos de preservación utilizados se estratificaron las cepas en cuatro grupos los cuales se muestran en la Tabla 3.

Un $67 \%$ del total de cepas de $E$. coli presentó un optimo porcentaje de recuperación tanto en papel fil- tro como por el método de criopreservación. En el $20 \%$ puede usarse la criopreservación como método Stock ideal y en el 7\% no debe usarse. Solo un 6\% de las cepas no podrá ser conservado en los métodos Stock y Semistock ensayados, Figura 5.

Además un $60 \%$ de las especies de Enterobacterias pueden ser conservadas tanto en criopreservación como en papel filtro, pero se podrían buscar métodos un poco más eficaces. También se encontró que ninguna de las especies de enterobacterias conservadas presentó una recuperación baja tanto en papel filtro como en criopreservación, Figura 6.

Finalmente, en la mayoría (75\%) de las Pseudomonas se debe buscar un método stock alternativo y si se usa la criopreservación, la densidad optima de preservación no debe ser inferior a 0.8 , pues la viabilidad posterior a la conservación sería baja, Figura 7.

En general, el 89\% de las cepas de E. coli pueden ser conservadas en criopreservación y el $74 \%$ en papel filtro, Figura 8.

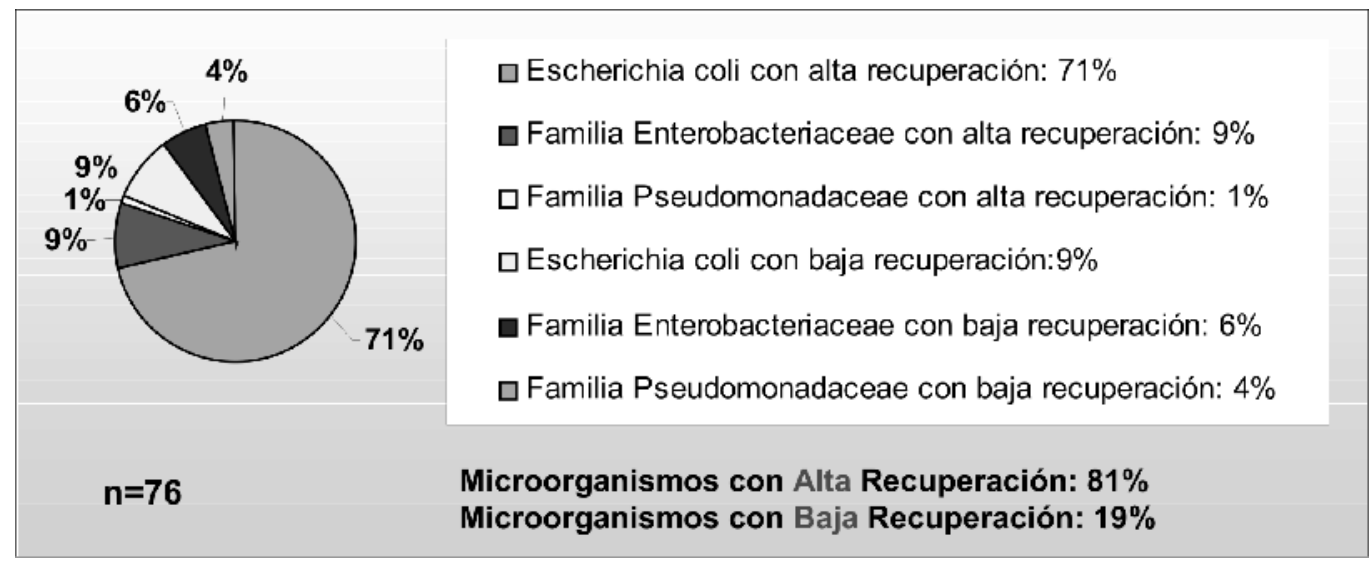

Figura 4. Porcentaje de recuperación a las 24 horas de criopreservación a $-70^{\circ} \mathrm{C}$. 


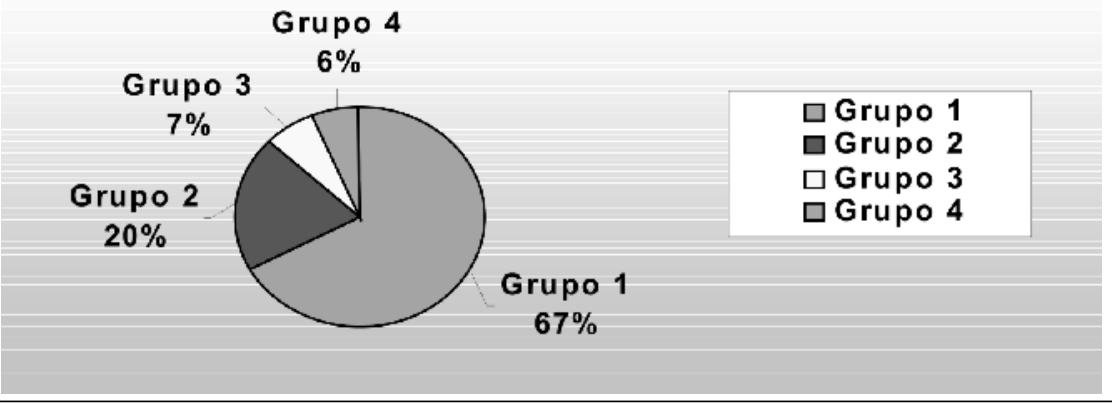

Figura 5. Comparación de los métodos de conservación de E. coli en papel filtro y criopreservación.

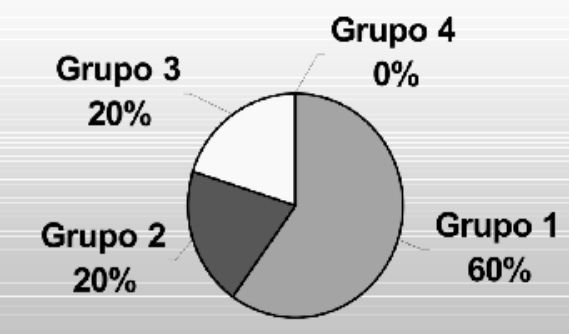

$\square$ Grupo 1

$\square$ Grupo 2

$\square$ Grupo 3

$\square$ Grupo 4

Figura 6. Comparación de los métodos de conservación de Enterobacterias en papel filtro y criopreservación.

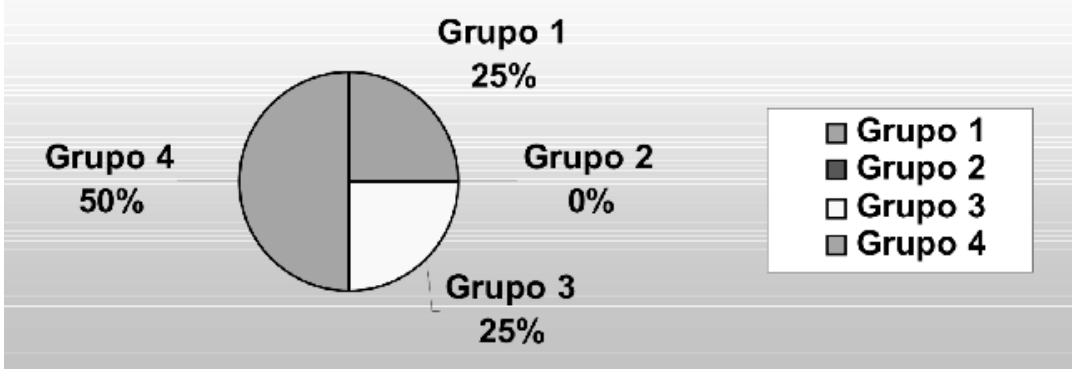

Figura 7. Comparación de los métodos de conservación de Pseudomonas en papel filtro y criopreservación.

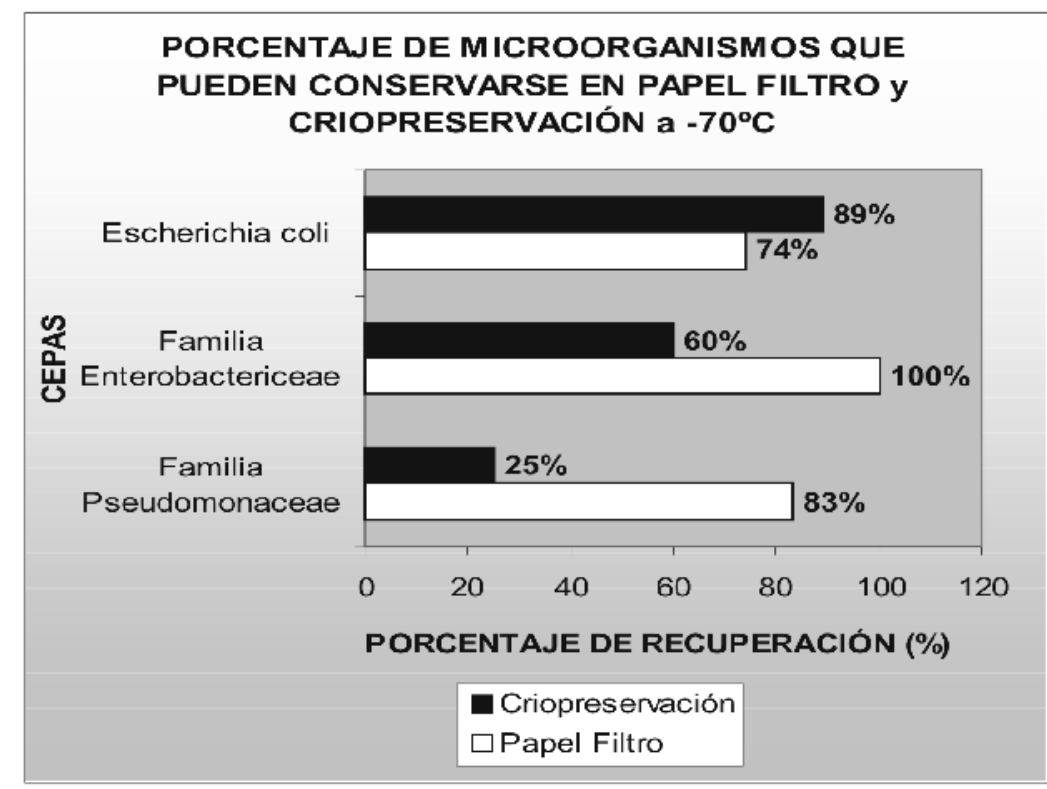

Figura 8. Porcentaje de microorganismos que pueden conservarse en papel filtro y criopreservación a $-70^{\circ} \mathrm{C}$, por presentar porcentajes de recuperación mayores al 50\% luego de 24 horas de conservación 
E1 100\% de las especies de la Familia Enterobacteriaceae pueden ser conservadas en papel filtro y el $60 \%$ en criopreservación; el $83 \%$ del total de las cepas de Pseudomonas pueden ser conservadas de manera optima en Papel filtro y el $25 \%$ en criopreservación, Figura 8.

\section{Sexta etapa. Documentación de protocolos y} diseño e implementación de la base de datos. Los protocolos fueron realizados en el transcurso del estudio obteniéndose los protocolos de recuperación de cepas conservadas a $4{ }^{\circ} \mathrm{C}$ y $-70^{\circ} \mathrm{C}$; además del protocolo de conservación de cepas por el método semistock en papel filtro y por el método stock de criopreservación a $-70^{\circ} \mathrm{C}$, así como el protocolo de recuento del cultivo inicial y viabilidad posterior a las 24 horas de conservación. Por otro lado, la base de datos se realizó en el software Access ${ }^{\circledR}$ y se implemento en el IBUN con éxito y en la página Web de la Universidad Nacional en la dirección electrónica www.ibun.unal.edu.co/instituto/cepario, para la consulta de los microorganismos del cepario, Figura 9. Entre los formularios con los que cuenta esta base se encuentran: taxonomía, características macro y microscópicas, conservación en papel filtro y criopreservación.

\section{Discusión}

De acuerdo a lo establecido por Espitia (2) en y Díaz (3), la recuperación de los microorganismos del cepario del IBUN fue realizada de manera adecuada, con los esquemas propuestos para cada género y especie de microorganismo. Los procedimientos en el presente estudio complementan los realizados en el IBUN en los años anteriores para la evaluación de la viabilidad y caracterización morfológica y bioquímica de las cepas $(2,3)$. Se pudo obtener las $\mathrm{UFC} / \mathrm{ml}$ y determinar el género y especie de microorganismo a conservar. Sin embargo, en el presente estudio se calculó la viabilidad en porcentaje de recuperación luego de la conservación y se realizaron

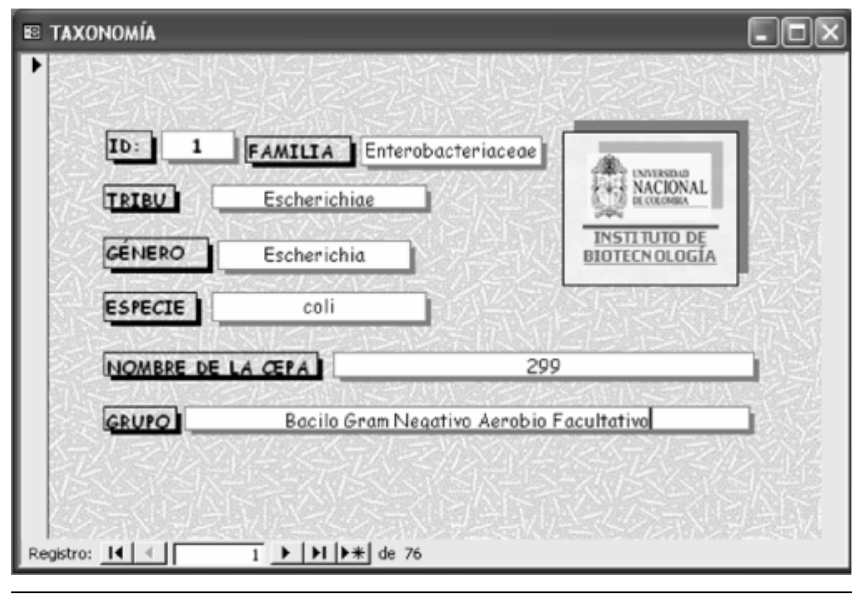

Figura 9. Imagen de la base de datos implementada en el cepario del IBUN y en la página web de la Universidad Nacional de Colombia.

los respectivos análisis, teniendo en cuenta estos cálculos; contrario a lo realizado en los anteriores proyectos nombrados, donde se estratifico la viabilidad en nula, escasa, moderada y alta, según los valores obtenidos en cada viabilidad, y a partir de esto realizaron los respectivos análisis $(2,3)$.

Como se observó en este estudio, en lo referente a la preservación realizada en papel filtro, Antheunisse en 1981 encontró que esta técnica fue adecuada para 13 géneros de bacterias incluyendo E.coli, Pseudomonas y otras Enterobacterias, con una buena o moderada supervivencia (11).

En el presente estudio, la preservación en papel filtro fue adecuada para Salmonella, donde a las 24 horas se presentó un porcentaje de recuperación alto para Salmonella enteritidis y Salmonella typhi, conforme a lo presentado por García y Uruburu, donde también se presentaron porcentajes de recuperación altos para este género que se mantuvieron por 2 años (5).

Realizando lo establecido en el manual de criopreservación de la ATCC por Frank, en 1998, se obtuvo una adecuada preservación de la familia Enterobacteriacea, incluyendo Escherichia coli (6). Gran parte de las cepas de E.coli presentaron porcentajes de recuperación mayores al 99\%, conforme a lo informado por Nagai con un porcentaje del $97,6 \%$, y Meza con uno del 100\% $(1,12)$. Lo mismo se corrobora con el estudio de estabilidad, a tiempo real por 
un período de 6 meses del método de criopreservación, realizado por Poutou en el 2002 con cepas de Escherichia coli, puesto que sus resultados indicaron que el almacenamiento a $-70^{\circ} \mathrm{C}$ y el empleo de un protocolo de descongelamiento rápido proporcionan una mayor recuperación celular manteniendo la viabilidad en un rango del 93-97\% (13).

Sin embargo, para Pseudomona y Proteus, los porcentajes de recuperación no fueron altos en el presente estudio, contrario a lo informado por Nagai, donde se presento un porcentaje de recuperación del 99\% y 100\% para Pseudomonas y Proteus, respectivamente (12).

Además, los buenos resultados obtenidos con el medio para la criopreservación usado por Gherna y MacFaddin, fueron comparables con los resultados en la criopreservación de la familia Enterobacteriacea, incluyendo Escherichia coli, en el presente proyecto $(7,8)$.

En el presente estudio se realizó una modificación en el agente crioprotector, que en el caso de E. coli, fue dimetilsulfoxido (DMSO), el cual es mejor agente crioprotector para este género, que el glicerol según lo descrito por Sharp y Fomin, quienes encontraron toxicidad del glicerol para esta bacteria, mientras que el DMSO proteje la superficie de los lipopolisacaridos de la misma contra los daños por congelación $(9,14)$.

Este agente crioprotector fue usado en concentraciones del 10\% según lo recomendado por Húbalek (15), con muy buenos resultados, contrario a lo descrito por Fomin, que encontró una inhibición en el crecimiento de E.coli a esta concentración (14). Es importante anotar, además, que según lo recomendado por Húbalek, se acorto el tiempo de exposición de las células al efecto nocivo del DMSO en el congelamiento y descongelamiento, manteniéndolas en baño de hielo durante estos períodos, con muy buenos resultados (15).

Además, en el presente estudio se permitió posterior a la criopreservación, un período de equilibración de 15 minutos a $4^{\circ} \mathrm{C}$ en el caso de DMSO, y en el caso del glicerol un período un poco mayor, con muy buenos resultados en el presente estudio, compara- bles con lo observado por Marcin (16) y Húbalek (15).

Respecto a la criopreservación de Pseudomonas con glicerol, esta no fue adecuada observándose bajos porcentajes de recuperación, conforme a lo establecido por Fomin, en el cual evidenció toxicidad del glicerol en Pseudomonas (14). Por otro lado, se usó con bajos porcentajes de recuperación una mezcla de 5\% de lactosa con $10 \%$ de glicerol, que contrario a lo descrito por Daily, no presentó mejores resultados que el glicerol y el DMSO solos, para este género (17).

Sin embargo, el glicerol fue usado adecuadamente para la criopreservación de Enterobacterias en una concentración del 10\%, confirmando lo observado por Húbalek, quien informo su uso con buenos resultados a la misma concentración para la mayoría de Enterobacterias (15).

Para la preservación de Klebsiella se ensayo como agente criprotector una solución de leche descremada al 20\%, con buenos resultados de viabilidad y un buen porcentaje de recuperación; como lo observado por Takahashi (18). Sin embargo, en este estudio la propiedad de homogeneidad no se mantuvo, por lo que se decidió conservar en medio Gherna con glicerol, donde además de la propiedad de viabilidad, se mantuvo la propiedad de homogeneidad.

Para la recuperación de los microorganismos conservados en papel filtro, se recomienda un periodo de incubación de 48 horas a $37^{\circ} \mathrm{C}$ en medio de recuperación, en el caso de E.coli y otras Enterobacterias. Así como la búsqueda de un método de conservación alternativo, sea stock o semistock, para los microorganismos que presentaron bajos porcentajes de supervivencia en estos.

Para la conservación de Pseudomonas se requiere que esta se realice lo más pronto posible posterior a la recuperación, debido a que en el presente estudio se observó una disminución en la viabilidad de estas luego de pasado algún tiempo después de la recuperación, por lo cual se debe buscar el mejor método de conservación para estas y realizarlo en el menor tiempo posible. 
Finalmente, la base de datos que fue elaborada conforme a lo planteado por Espitia (2), se implementó con éxito en la página Web del IBUN, con la información relevante de los microorganismos conservados. Esta fue complementada con información de bases de datos consultadas en la Web, tales como la Centraalbureau voor Schimmelcultures (CBS), de donde se agregó el grupo de riesgo (19), la World Federation for culture Collections (WFCC), de donde se obtuvo lo referente a la viabilidad de microorganismos. (20) y la Belgian Coordinated Collections of Microorganisms (BCCM) de donde se tuvó en cuenta las condiciones de cultivo y almacenamiento (21).

\section{Agradecimientos}

Queremos agradecer de manera especial a Colciencias, por el patrocino de este proyecto y al Instituto de Biotecnología de la Universidad Nacional de Colombia, por el préstamo de sus instalaciones, materiales y equipos.

También a la Universidad Nacional de Colombia y a la Universidad Colegio Mayor de Cundinamarca por brindarnos su colaboración en la elaboración de este estudio.

\section{Referencias}

1. Meza R, Monroy A, Mercado M, Poutou R, Rodríguez P, Pedroza A. Study of the stability in real time of cryopreserved strain banks. Universitas Scientiarum. 2004; 9(2):35-42

2. Espitia S, García Y. 1999. Caracterización y sistematización del banco de genes y cepas del Instituto de Biotecnología de la Universidad Nacional. Bacteriología y Laboratorio Clínico. Colombia, Universidad Colegio Mayor de Cundinamarca, Facultad de Ciencias de la Salud, 120 p.

www.unicolmayor.edu.co
3. Díaz M. 2004. Manual de procedimientos banco de cepas y genes. Bacteriología y Laboratorio Clínico. Colombia, Universidad Colegio Mayor de Cundinamarca, Facultad de Ciencias de la Salud, $50 \mathrm{p}$.

4. Kirsop B, Doyle A. 1991. Maintenance of microorganisms and cultured cells; A manual of laboratory methods. $2^{\text {nd }}$ ed. London, Academic Press. 308p

5. Uruburu F. La sociedad española de microbiología y el aseguramiento de la calidad microbiológica. Actualidad SEM. 1997; 28: 12-13.

6. Frank P, Simione M. 1998. Cryopreservation Manual Nalge Nunc International. INTERNET: http:// www.nalgenelabware.com/techdata/technical/cryo.pdf (Marzo, 27, 2006)

7. MacFaddin J. 1985. Media for isolation-cultivationidentification maintenance of medical bacteria. USA. Williams \& Wilkins. v. 1. 524p.

8. Gherna R. 1994. In Gerhardt, Murray, Wood and Krieg (ed.). Methods for general and molecular bacteriology. American society for microbiology. Washington, D.C. pp.278-292.

9. Sharp R. The preservation of genetically unstable microorganisms and the cryopreservation of fermentation seed cultures. Adv Biotechnol Processes. 1984; 3: 81-109

10. Silva J. TLA-1: A new plasmid-mediated extended-spectrum B-lactamase from Escherichia coli. Antimicrob Agents Chemother. 2000; 44(4): 997-1003

11. Antheunisse J. Survival of microorganisms after drying and storage. Antonie van Leeuwenhoek. 1981; 47(6): 539-545

12. Nagai T. Evaluation of preservation techniques of microorganism resources in the maff genebank. Jarq. 2005; 39:19-27

13. Poutou R. 2002. Estudio de Estabilidad a Tiempo Real de Bancos de Cepas Criopreservados en Glicerol al 10\% v/v. In: III Congreso Internacional de Microbiología Industrial. Bogotá, Colombia.

14. Fomin D, Alycheva I, Veselovskaya L, Tatchin S. Antibacterial properties of dimethylsulphoxide (in Russian), In: Khimioterapia infektsiy i lekarstvennoy ustoychivosti patogennych mikroorganizmov. Rusia, Moskva; 1983: pp. 63-64

15. Hubàlek Z. Review: Protectans used in the cryopreservation of microorganisms. Cryobiology, 2003; 46 (3):205-229

16. Marcin A, Gyulai F, Arady J, Sorokov M. A Simple Technique for Cryopreservation of the rumen protozoa Entodinium simplex. Cryo-Letters. 1989; 10: 89-104

17. Daily W, Higgens C. Preservation and storage of microorganisms in the gas phase of liquid nitrogen. Cryobiology. 1973;10: 364-367

18. Takahashi M. Effects of freezing and thawing and storage by freezing on the biological and morphological properties of strain K-9 of Klebsiella pneumoniae and its variants. Z Allg Mikrobiol. 1982; 22(9):649-60.

19. Centraalbureau voor Schimmelcultures. 2006. Kinds of microorganisms that may be deposited. INTERNET: http:// www.cbs.knaw.nl/patents/index.htm (Julio, 17, 2006) 